\title{
PEMODELAN SISTEM ANTRIAN MULTI-CHANNEL JASA TELLER PADA BANK SYARIAH DI YOGYAKARTA UNTUK MENINGKATKAN KINERJA PERUSAHAAN
}

\author{
Noor Saif Muhammad Mussafi \\ Program Studi Matematika Fakultas Sains dan Teknologi UIN Sunan Kalijaga \\ J1. Marsda Adisucipto 1 Yogyakarta 55281, noor.mussafi@uin-suka.ac.id
}

\begin{abstract}
ABSTRAK
Antrian pada jasa perbankan syariah merupakan suatu permasalahan yang berkaitan dengan kenyamanan nasabah. Sistem antrian yang efisien dengan sendirinya dapat meningkatkan kepuasan nasabah dan tentunya akan berimbas pada kualitas kinerja perusahaan. Penelitian ini bertujuan untuk menganalisis karakteristik antrian, distribusi pola kedatangan dan pola pelayanan, serta memodelkan sistem antrian yang terjadi pada layanan teller di Bank Syariah di Yogyakarta. Output pemodelan tersebut kemudian dijadikan sebagai bahan kajian untuk mengukur kinerja dan optimalisasi sistem antrian. Beberapa kerangka teori yang diperlukan dalam menganalisa permasalahan tersebut diantaranya yaitu multi-channel queuing system, distribusi Poisson, uji Kolmogorov-Smirnov, dan pengukuran steady state. Hasil dari penelitian ini adalah pemodelan sistem antrian Bank Syariah di Yogyakarta yaitu

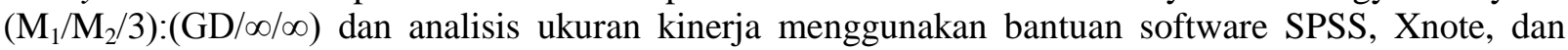
Microsoft Excel.
\end{abstract}

Kata Kunci: multi-channel queuing system, uji Kolmogorov-Smirnov, distribusi Poisson, steady state.

\begin{abstract}
QueuesonIslamic bankingservicesis a problemrelated tocustomer convenience. Efficientqueuing systemby itselfcan improvecustomersatisfactionand will certainlyimpact onthe quality ofthe company's performance. This studyaimed toanalyze the characteristics ofthe queue, the distributionpatterns ofarrivalandpatterns ofservice, as well asmodeling thequeuing systemthat occurs inthe servicetelleratBankSyariahinYogyakarta. Outputmodelingis thenusedas astudyto measure the performanceandoptimization ofqueuingsystems. Sometheoretical frameworkis neededin analyzingthese issuesamong whichmulti-channel queuingsystem, Poissondistribution, the Kolmogorov-Smirnov test, and measuringsteady state. Results from this study are queuing system modeling BankSyariahinYogyakarta, namely $\left(\mathrm{M}_{1} / \mathrm{M}_{2} / 3\right):(\mathrm{GD} / \infty / \infty)$ and analysis of performance measurement using SPSS, XNote, and Microsoft Excel .
\end{abstract}

Keywords: multi-channel queuing system, Kolmogorov-Smirnov test, Poisson distribution, steady state.

\section{Pendahuluan}

Seiring dengan pertumbuhan

populasi penduduk di Indonesia yang tidak diimbangi dengan infrastruktur yang memadai, antrian sudah menjadi bagian dari pengalaman sehari-hari. Jasa merupakan sektor ekonomi yang berkembangsecara cepat dan jasa merupakan sektor ekonomi terbesar 
dalam masyarakat maju(Heizerdan Render, 2005).

Para peneliti riset operasi telah mempelajari secara intensif mengenai struktur dan manajemen antrian dalam rangka efisiensi biaya yang ditimbulkan dalam sistem antrian dan sebagian besar menggunakan model matematika (Gross and Harris 1985; Newell 1982).Secara teoritis panjang antrian, masa tunggu dan fasilitas layanan merupakan tiga hal yang saling mempengaruhi dalam suatu sistem antrian dalam pengambilan keputusan.

Salah satu perusahaan yang bergerak dibidang jasa adalah perbankan dan merupakan sektor penting dalam perekonomian suatu negara. Pertumbuhan penduduk yang terus meningkat dan keterbatasan jumlah bank yang tersedia dikhawatirkan dapat mengakibatkan pelayanan kurang optimal. Salah satu indikatornya adalah nasabah harus mengantri lama untuk mendapatkan pelayanan jasa teller di bank yang jika dibiarkan maka dapat menyebabkan nasabah keluar dari sistem.Sehingga masalah antrian harus segera menjadi prioritas untuk ditemukan jalan keluarnya. Dalam penelitian sebelumnya, pada sektor jasa lain yaitu SPBU, sistem antrian dengan karakter single channel single phase, Noor Saif Muhammad Mussafi (2011) melakukan penelitian yang berjudul PenerapanSingle Channel Queuing Model (SCQM) dalam Optimalisasi Pelayanan Jasa SPBU di
Kota Yogyakarta menunjukkan bahwa performa perusahaan dapat ditingkatkan hingga $19,39 \%$ melalui analisis teori antrian.

Untuk mengetahui sistem antrian yang tepat pada Bank Syariah di Yogyakarta yang memiliki perbedaan karakter sistem antrian dengan SPBU, maka diperlukan sebuah penelitian lebih lanjut dengan cara menganalisa efisiensi layanan dari teller ini agar dapat diketahui bagaimana karakter sistem antrian, pemodelan sistem antrian, ukuran kinerja dan optimalisasi sistem antrian.

\section{Teori Antrian}

Teori antrian merupakan salah satu obyek kajian menarik dalam riset operasi. Tujuan analisis antrian yaitu memberikan bukti ilmiah tentang estimasi pelayanan untuk mengurangi dampak antrian konsumen (Hamdy A. Taha, 2007). Bukti ilmiah tersebut terkait dengan perhitungan kualitas pelayanan pada antrian seperti rata-rata masa tunggu dalam antrian dan produktifitas fasilitas pelayanan yang kemudian digunakan untuk mendesain sistem antrian. Sekalipun teori antrian merupakan bagian dari riset operasi, namun analisisnya tidak menggunakan optimalisas imelainkan distribusi probabilitas dan pemodelan matematika. Pada prinsipnya sistem antrian menjelaskan dua proses besar yaitu proses input dan proses output. Proses input berkaitan dengan 
kedatangan konsumen dan proses output berkaitan dengan pelayanan. Di samping itu, menurut (Levin, Richard I., 1992) dalam sistem antrian dikenal tiga komponen yaitu:

a. Kedatangan

Pola kedatangan acak (random) dapat digambarkan dengan distribusi probabilitas poisson.

b. Antrian

Panjang antrian bisa terbatas (limited) dan bisa juga tidak terbatas (unlimited).

c. Fasilitas pelayanan

Karakteristik dari fasilitas pelayanan yaitu tata letak dari sistem antrian, disiplin antrian, dan waktu pelayanan.

Tata letak dari sistem antrian digambarkan dengan pola layanan yaitu sistem antrian jalur tunggal satu jenis layanan (single channel, single phase), sistem antrian jalur tunggal tahapan berganda (single channel, multi phases), sistem antrian jalur berganda satu tahap (multi channel, single phase), dan sistem antrian jalur berganda dengan tahapan berganda (multi channel, multi phases). Karakteristik waktu pelayanan yang dibutuhkan adalah konstan (jika waktu pelayanan relatif sama untuk setiap pelanggan) dan acak (jika waktu yang dibutuhkan tiap konsumen berbedabeda). Untuk waktu pelayanan acak, diasumsikan mengikuti distribusi eksponensial.

\section{Notasi Model Antrian}

Untuk memahami beberapa model antrian tersebut maka dibuat suatu standar umum yang dikenal dengan notasi Kendall. Format umum model tersebut yaitu (A / B / C) : (D / E / F) dengan keterangan sebagai berikut.
$\mathrm{A}=$ Distribusi kedatangan
$\mathrm{B}=$ Distribusi waktu pelayanan
$\mathrm{C}=$ Jumlah fasilitas pelayanan $(c=1,2,3, \ldots)$
$\mathrm{D}=$ Disiplin layanan, seperti LCFS, GD, FCFS, dan lain-lain
$\mathrm{E}=$ Jumlah konsumen maksimum dalam system
$\mathrm{F}=$ Ukuran pemanggilan populasi / sumber

\section{Ukuran Steady-State Dari Kinerja}

Kondisi steady-state dapat terpenuhi jika $\lambda<\mu$ sehingga $\rho=\frac{\lambda}{\mu}<1$ dimana $\lambda$ adalah rata-rata jumlah kedatangan dan $\mu$ adalah rata-rata laju pelayanan. Berdasarkan informasi tersebut dapat dihitung ukuran-ukuran kinerja, yaitu jumlah nasabah yang diperkirakan dalam sistem $\left(L_{s}\right)$, jumlah nasabah yang diperkirakan dalam antrian $\left(L_{q}\right)$, waktu menunggu yang diperkirakan dalam sistem $\left(W_{s}\right)$, dan waktu menunggu yang diperkirakan dalam antrian $\left(W_{q}\right)$.

\section{Distribusi Poisson}

Dalam teori probabilitas, distribusi poisson merupakan distribusi probabilitas diskrit yang menunjukkan probabilitas 
suatu kejadian pada periode tertentu (jika kejadian tersebut diketahui rata-ratanya) dan bebas satu sama lain. Menurut Haight (1967), misal kedatangan diasumsikan terjadi dengan kecepatan rata-rata konstan dan bebassatu sama lain, maka probabilitas $n$ kedatangan dalam waktu $T$ dinyatakan dengan formula:

$$
P(n, T)=\frac{e^{-\lambda T}(\lambda T)^{n}}{n !}, n=0,1,2, \ldots
$$

Keterangan: $\quad \lambda=\quad$ rata-rata jumlahkedatangan per satuanwaktu, $T=$ periode waktu, $n=$ jumlah kedatangan dalam waktu $T$, dan $P(n, T)=$ probabilitas $n$ kedatangan dalam waktu $T$.

Jika kedatangan mengikuti distribusi Poisson maka dapat ditunjukkan secara matematis bahwa waktu antar kedatangan akan terdistribusi sesuai dengan distribusi eksponensial yaitu $P(T \leq t)=1-$ $e^{-\lambda t}, \quad 0 \leq t \leq \infty$.

\section{Uji Distribusi}

Salah satu uji distribusi yang dapat digunakan yaitu uji KolmogorovSmirnov. Menurut Daniel (1989), langkah-langkah dalam uji tersebut yaitu:

a. Menentukan hipotesis

$H_{0}=$ distribusi yang diambil dari populasi berdistribusi A

$H_{1}=$ distribusi yang diambil tidak berasal dari populasi berdistribusi A

b. Statistik Uji

Tes satu sampel Kolmogorov-Smirnov

c. Taraf Signifikansi dan Kriteria uji
Misal taraf signifikansi $\alpha=5 \%$. Tolak $H_{0}$ jika nilai signifikansi $\leq$ $\alpha=5 \%$.

\section{Model Antrian Parallel Channel (M/M/c):(GD/ $/ \infty)$}

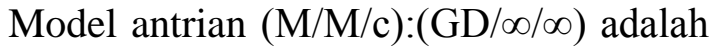
model antrian dengan pola kedatangan $\lambda$ dan pola pelayanan $\mu$ serta jumlah fasilitas pelayanan sebanyak $c$. Disiplin antrian yang digunakan pada model ini adalah FCFS (First Come First Service), kapasitas maksimum yang diperbolehkan dalam sistem adalah tak hingga, dan memiliki sumber pemanggilan tak hingga. Menurut Gross (1985) dan Taha (2007), beberapa formula untuk mengetahui ukuran-ukuran kinerja pada

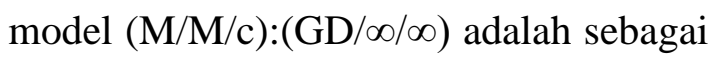
berikut:

$$
\begin{gathered}
P_{0}=\frac{1}{\left[\sum_{n=0}^{c-1} \frac{1}{n !} \rho^{n}\right]+\frac{1}{c !}(\rho)^{c}\left(\frac{c \mu}{c \mu-\lambda}\right)} \\
L_{q}=\left(\frac{\rho^{c+1}}{(c-1) !(c-\rho)^{2}}\right)\left(\sum_{n=0}^{c-1} \frac{\rho^{n}}{n !}\right. \\
\left.+\frac{\rho^{c}}{c !\left(1-\frac{\rho}{c}\right)}\right)^{-1}
\end{gathered}
$$

$$
\begin{aligned}
L_{s}= & \left(\frac{\rho^{c+1}}{(c-1) !(c-\rho)^{2}}\right)\left(\sum_{n=0}^{c-1} \frac{\rho^{n}}{n !}\right. \\
& \left.\quad+\frac{\rho^{c}}{c !\left(1-\frac{\rho}{c}\right)}\right)^{-1}+\rho \\
= & L_{q}+\rho
\end{aligned}
$$


$W_{q}$

$$
\begin{gathered}
=\frac{\left(\frac{\rho^{c+1}}{(c-1) !(c-\rho)^{2}}\right)\left(\sum_{n=0}^{c-1} \frac{\rho^{n}}{n !}+\frac{\rho^{c}}{c !\left(1-\frac{\rho}{c}\right)}\right)^{-1}}{\lambda} \\
=\frac{L_{q}}{\lambda}
\end{gathered}
$$$$
W_{s}
$$$$
=\frac{\left(\frac{\rho^{c+1}}{(c-1) !(c-\rho)^{2}}\right)\left(\sum_{n=0}^{c-1} \frac{\rho^{n}}{n !}+\frac{\rho^{c}}{c !\left(1-\frac{\rho}{c}\right)}\right)^{-1}}{\lambda}
$$$$
+\frac{1}{\mu}
$$

$$
=W_{q}+\frac{1}{\mu}
$$

dimana $\rho=\frac{\lambda}{\mu}$

Berdasarkan asumsi tersebut dapat diperoleh hasil secara statistik seperti probabilitas fasilitas layanan sibuk, jumlah rata-rata dalam antrian, jumlah rata-rata di dalam sistem (baik yang antri maupun yang sedang dilayani), waktu rata-rata di dalam antrian, dan waktu ratarata di dalam sistem.

\section{Metodologi Penelitian}

Secara umum metode penelitian ini mencakup dua aspek penting yaitu (1) jenis dan sumber data dan (2) teknik analisis data.

\section{Jenis danSumber Data}

Proses analisis dalam penelitian yang menekankan pada bidang riset operasi ini memperhatikan kaidahkaidah analisis, pemodelan, dan statistika. Objek dari penelitian ini adalah Bank Syariah di Yogyakarta yaitu Bank Syariah Mandiri dan bank
BNI Syariah. Sedangkan populasi dalam penelitian ini adalah nasabah bank yang mengantri untuk dilayani. Pengambilan data primer dilakukan secara acak sederhana dalam tenggang waktu tertentu yaitu tiga hari kerja pada pukul 09.00 sampai 15.00 WIB.

\section{Teknik Analisis Data}

Adapun teknik analisis data dalam penelitian ini dapat dibagi menjadi tiga tahapan.

- Tahap pertama, data primer dari suatu perusahaan terlebih dahulu diidentifikasi kelengkapan dan akurasinya. Pengambilan sampel menggunakan software XNote. Selanjutnya disusun ilustrasi sistem antrian.

- Tahap kedua, pengujian kondisi steady state dan uji distribusi kedatangan dan waktu pelayanan menggunakan uji KolmogorovSmirnov.

- Tahap ketiga adalah data-data pada tahap kedua akan dianalisis menggunakan multi channel queuing model. Selanjutnya akan diberikan kesimpulan sekaligus rekomendasi atas hasil analisis terkait dengan sistem antrian (yang telah dievaluasi).

\section{Hasil dan Pembahasan}

Secara garis besar pada bab ini akan dijelaskan mengenai ilustrasi sistem 
antrian, steady state kinerja sistem antrian, uji distribusi kedatangan dan waktu pelayanan, serta analisis dan ukuran kinerja sistem antrian.

\section{Ilustrasi Sistem Antrian}

Dalam layanan jasa perbankan, teller merupakan salah satu bagian paling penting dalam melayani transaksi nasabah. Pada hari biasa baik Bank Syariah Mandiri maupun BNI Syariah masing-masing melayani nasabah dengan menyediakan 3 (tiga) teller dengan jenis pekerjaan yang sama yaitu transaksi keuangan. Seiring dengan meningkatnya nasabah, maka selama 5 (lima) hari kerja kedua bank tersebut selalu membuka 3 (tiga) teller sekaligus. Agar dapat dengan mudah dipahami, Gambar 1 menunjukkan ilustrasi sistem antrian pada kedua bank.

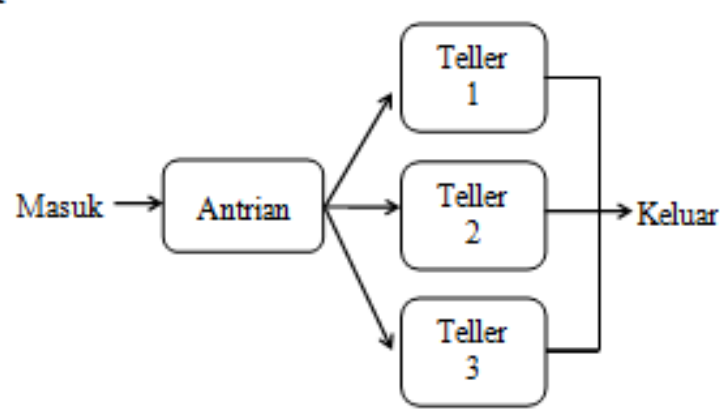

Gambar 1. Ilustrasi sitem antrian

\section{Steady State Kinerja Sistem Antrian}

Berdasarkan Tabel 1 (ukuran steady state), dapat diidentifikasi bahwa tingkat utilitas fasilitas pelayanan untuk nasabah pada Bank Syariah Mandiri dan Bank BNI Syariah sama-sama menghasilkan nilai kurang dari satu. Sehingga dapat disimpulkan bahwa sistem antrian di teller kedua bank tersebut memenuhi kondisi steady state, artinya bahwa rata-rata tingkat kedatangan nasabah tidak melebihi ratarata tingkat pelayanan.

Tabel 1. Tingkat Utilitas dan kondisi Steady State

\begin{tabular}{cccccc}
\hline $\begin{array}{c}\text { Nama } \\
\text { Bank }\end{array}$ & $c$ & $\lambda$ & $\mu$ & $\rho=\frac{\lambda}{c \mu}$ & $\begin{array}{c}\text { Steady } \\
\text { State }\end{array}$ \\
\hline $\begin{array}{c}\text { Bank } \\
\text { Syariah } \\
\text { Mandiri } \\
\text { BNI } \\
\text { Syariah }\end{array}$ & 3 & 8,733 & 7,667 & 0,379 & Ya \\
\hline
\end{tabular}

\section{Uji Distribusi Kedatangan Dan Waktu Pelayanan}

a. Uji Distribusi Kedatangan

$\mathrm{H}_{0}$ : Kedatangan pasien berdistribusi Poisson

$\mathrm{H}_{1}$ : Kedatangan pasien tidak berdistribusi Poisson

Taraf Signifikansi: $\alpha=5 \%$

Kriteria Uji: $\mathrm{H}_{0}$ diterima karena menurut Gambar 2 Asymp. Sig. (2-tailed) = 0,998 $>\alpha=0,05$.

Berdasarkan hasil uji KolmogorovSmirnov dapat disimpulkan bahwa data tingkat kedatangan nasabah Bank Syariah Mandiri berdistribusi Poisson. Adapun data tingkat kedatangan nasabah Bank BNI Syariah juga berdistribusi Poisson karena Asymp. Sig. (2-tailed) = $0,779>\alpha=0,05$.

b. Uji Distribusi Waktu Pelayanan

$\mathrm{H}_{0}$ : Waktu pelayanan nasabah berdistribusi Eksponensial 
$\mathrm{H}_{1}$ : Waktu pelayanan nasabah tidak berdistribusi Eksponensial

Taraf Signifikansi: $\alpha=5 \%$

Kriteria Uji: $\mathrm{H}_{0}$ diterima karena menurut Gambar 3 Asymp. Sig. (2-tailed) = $0,055>\alpha=0,050$.

Berdasarkan hasil uji KolmogorovSmirnov dapat disimpulkan bahwa data waktu pelayanannasabah Bank Syariah Mandiri berdistribusi Eksponensial. Adapun data waktu pelayanannasabah Bank BNI Syariah juga berdistribusi Eksponensial karena Asymp. Sig. (2-tailed) $=0,079>\alpha=0,05$

Tabel 2. Output SPSS Distribusi Kedatangan

One-Sample Kolmogorov-Smirnov Test

\begin{tabular}{|ll|r|}
\hline & & VAR00001 \\
\hline $\mathrm{N}$ & 15 \\
Poisson Parameter ${ }^{\mathrm{a}, \mathrm{b}}$ & Mean & 8,7333 \\
Most Extreme & Absolute &, 101 \\
Differences & Positive &, 101 \\
& Negative &,- 066 \\
Kolmogorov-Smirnov Z &, 392 \\
Asymp. Sig. (2-tailed) &, 998 \\
\hline
\end{tabular}

Tabel 3. Output SPSS Distribusi Waktu Pelayanan

One-Sample Kolmogorov-Smirnov Test

\begin{tabular}{|ll|r|}
\hline & & VAR00004 \\
\hline $\mathrm{N}$ & & 15 \\
Exponential parameter. & a,b & Mean \\
Most Extreme & Absolute &, 6667 \\
Differences & Positive &, 161 \\
& Negative &,- 346 \\
Kolmogorov-Smirnov Z & & 1,339 \\
Asymp. Sig. (2-tailed) & &, 055 \\
\hline
\end{tabular}

\section{Analisis Dan Ukuran Kinerja Sistem Antrian}

Berdasarkan hasil analisis terhadap distribusi kedatangan, waktu pelayanan dan kondisi steady state sistem antrean maka dapat ditentukan bahwa model sistem antrean Bank Syariah di Yogyakarta adalah $\left(\mathrm{M}_{1} / \mathrm{M}_{2} / 3\right):(\mathrm{GD} / \infty / \infty)$ seperti pada Tabel 2 (uji distribusi dan model antrian).

Tabel 4. Uji Kesesuaian Distribusi dan Model Antrian

\begin{tabular}{cccc}
\hline Nama & Uji & Uji & Model Antrian \\
Bank & Distribus & Distribusi & \\
& $\mathrm{i}$ & Waktu & \\
& Kedatan & Pelayanan & \\
& gan & & \\
& & &
\end{tabular}

\begin{tabular}{|c|c|c|c|}
\hline $\begin{array}{l}\text { Bank } \\
\text { Syaria } \\
\text { h } \\
\text { Mand } \\
\text { iri }\end{array}$ & Poisson & $\begin{array}{c}\text { Eksponen } \\
\text { sial }\end{array}$ & $\begin{array}{c}(\mathrm{M} / \mathrm{M} / 3):(\mathrm{GD} / \\
\infty / \infty)\end{array}$ \\
\hline $\begin{array}{l}\text { BNI } \\
\text { Syaria } \\
\text { h }\end{array}$ & Poisson & $\begin{array}{l}\text { Eksponen } \\
\text { sial }\end{array}$ & $\begin{array}{c}(\mathrm{M} / \mathrm{M} / 3):(\mathrm{GD} / \\
\infty / \infty)\end{array}$ \\
\hline
\end{tabular}

Model tersebut adalah model sistem antrean dengan distribusi kedatangan nasabah Poisson,distribusi waktu pelayanan Eksponensial danjumlah teller yang beroperasi sebanyak tiga dengan aturan pertama datang pertama dilayani (First Come First Service).

Secara umum ukuran kinerja sistem antrian berdasarkan data primer dapat disajikan pada Tabel 3 yang dapat dimaknai: 
a. Probabilitas petugas teller menganggur di Bank Syariah Mandiri dan Bank BNI Syariah berturut-turut adalah 0,314 dan 0,315 .

b. Waktu menunggu yang diperkirakan dalam sistem di Bank Syariah Mandiri dan Bank BNI Syariah berturut-turut adalah0,137 dari satu

Tabel 3. Tingkat Kegunaan Fasilitas Pelayanan

\begin{tabular}{ccccccccc}
\hline Nama Bank & $c$ & $\lambda$ & $\mu$ & $L_{s}$ & $L_{q}$ & $W_{s}$ & $W_{q}$ & $P_{0}$ \\
\hline $\begin{array}{c}\text { Bank Syariah } \\
\text { Mandiri }\end{array}$ & 3 & 8,733 & 7,667 & 1,205 & 0,066 & 0,137 & 0,007 & 0,314 \\
BNI Syariah & 3 & 11,467 & 10,067 & 1,215 & 0,076 & 0,105 & 0,006 & 0,315 \\
\hline
\end{tabular}

\section{Kesimpulan}

Setelah melakukan pengkajian mengenai sistem antrian pada Bank Syariah di Yogyakarta, dapat disimpulkan bahwa:

1. Model antrian untuk layanan jasa teller pada Bank Syariah di Yogyakarta adalah $\left(\mathrm{M}_{1} / \mathrm{M}_{2} / 3\right):(\mathrm{GD} / \infty / \infty)$ berbasis First Come First Service.

2. Berdasarkan nilai-nilaipada ukuran kinerja yang diperoleh (probabilitas petugas menganggur sekitar 30\% dan waktu menunggu dalam sistem tidak lebih dari 8,22 menit), maka secara umum dapat dikatakan pelayanan pada Bank Syariah di Yogyakarta dalam kondisi yang efektif.

\section{Ucapan Terima Kasih}

Penulis mengucapkan terima kasih kepada Lembaga Penelitian dan Pengabdian Masyarakat (LPPM) UIN Sunan Kalijaga atas skema pendanaan penelitian pada tahun 2015 tersebut. Selanjutnya diucapkan terima kasih kepada Azzunisa Mahanani dan Sirni Suryani, keduanya merupakan mahasiswa tingkat akhir Matematika UIN Sunan Kalijaga atas bantuan teknisnya dalam pengambilan data.

\section{Pustaka}

Daniel, W.W. (1989), Statistika Nonparametrik Terapan. Jakarta: PT Gramedia.

Frank A. Haight (1967), Handbook of the Poisson Distribution. New York: John Wiley \& Sons. 
Gross, Donald and Carl Harris (1985),

Fundamentals of Queueing

Theory, New York: Wiley.

Hamdy A. Taha (2007), Operations Research: an Introduction, Prentice Hall, NJ.

Heizerdan Render (2005),Operation Management, $\quad 7^{\text {th }} \quad$ edition. (Manajemen Operasi edisi 7, Buku 1 ) Penerbit Salemba Empat. Jakarta.

HendradanHelfiNasution (2012), Analisis Efisiensi Waktu Layanan Pada Sistem Administrasi. Jurnal ELKHA Vol.4, No 2.

Newell, Gordon (1982), Applications of Queueing Theory, New York: Chapman \& Hall.

Ivo A., Jacques Resing (2002), Queueing Theory, Lecture Notes, Department of Mathematics and Computing Science Eindhoven University of Technology.

Larson, Richard (1987), Perspectives on Queues: Social Justice and the Psychology of Queueing, Operations Research, Vol. 35 (November/December), 895-905.

Lee J. Bain, Max Engelhardt (2000), Introduction to Probability and Mathematical Statistics, Second Edition, Duxbury Press.
Levin, Richard I. (1992), Quantitative Approaches to Management, Eight edition, New York, McGraw-Hill International Editions.

Levin, Rich (2000), Retailers Find a Winning Mix, InformationWeek, 803 (September 11), 345-354.

Rongrong Zhou and DilipSoman (2003), Looking Back: Exploring the Psychology of Queueing and the Effect of the Number of People Behind, Journal of Consumer Research, Vol. 29, March, 517530.

Rongrong Zhou and DilipSoman (2008), Consumers Waiting in Queues: The Role of First-order and Second-order Justice, Psychology and Marketing, Vol. 25, March, 262-279.

Wayne L. Winston (2003), Operations Research: Applications and Algorithms, Third Edition, Duxbury Press.

Zhang Laifu Joel, Ng Wen Wei Jonathan Louis, and TaySengChuan (2000), Discrete-Event Simulation Of Queueing Systems, Proceedings of the Sixth Youth Science Conference, Ministry of Education, Singapore 
